\title{
Characteristics of Spring Phenological Changes in China over the Past 50 Years
}

\author{
Junhu Dai, ${ }^{1}$ Huanjiong Wang, ${ }^{1,2}$ and Quansheng Ge ${ }^{1}$ \\ ${ }^{1}$ Institute of Geographical Sciences and Natural Resources Research, Chinese Academy of Sciences, A 11, \\ Datun Road, Chaoyang District, Beijing 100101, China \\ ${ }^{2}$ University of Chinese Academy of Sciences, 19A Yuquan Road, Beijing 100049, China \\ Correspondence should be addressed to Quansheng Ge; geqs@igsnrr.ac.cn
}

Received 13 February 2014; Revised 18 March 2014; Accepted 18 March 2014; Published 7 April 2014

Academic Editor: Dong Jiang

Copyright (C) 2014 Junhu Dai et al. This is an open access article distributed under the Creative Commons Attribution License, which permits unrestricted use, distribution, and reproduction in any medium, provided the original work is properly cited.

In order to understand past plant phenological responses to climate change in China (1963-2009), we conducted trends analysis of spring phenophases based on observation data at 33 sites from the Chinese Phenological Observation Network (CPON). The phenological data on first leaf date (FLD) and first flowering date (FFD) for five broad-leaved woody plants from 1963 to 2009 were analyzed. Since most phenological time series are discontinuous because of observation interruptions at certain period, we first interpolated phenological time series by using the optimal model between the spring warming (SW) model and the UniChill model to form continuous time series. Subsequently, by using regression analysis, we found that the spring phenophases of woody plants in China advanced at a mean rate of 0.18 days/year over the past 50 years. Changes of spring phenophases exhibited strong regional difference. The linear trends in spring phenophases were $-0.18,-0.28,-0.21,-0.04$, and -0.14 days/year for the Northeast China Plain, the North China Plain, the Middle-Lower Yangtze Plain, the Yunnan-Guizhou Plateau, and South China, respectively. The spatial differences in phenological trends can be attributed to regional climate change patterns in China.

\section{Introduction}

Plant phenology, which is the study of seasonal plant development events and their relationship to environmental factors [1], has attracted much attention in the context of climate change $[2,3]$. Plant phenophases can be directly affected by the interannual variations of climate factors, such as temperature, light, and moisture [4]. Also, phenology can in turn affect climate $[5,6]$. For example, a longer presence of green cover in large areas should alter physical processes such as albedo, latent and sensible heat, and turbulence [5]. Moreover, a longer growing season can influence ecosystem productivity and vegetation-atmosphere $\mathrm{CO}_{2}$ exchange $[7,8]$. Thus, the study of past phenological changes is beneficial for assessing the impacts of climate change [9].

In recent years, pronounced phenological shifts have been detected on all the continents of the world based on satellite reflectance data [10-12] or ground observation data [1317]. For example, using the Advanced Very High Resolution Radiometer (AVHRR) Normalized Difference Vegetation
Index (NDVI) dataset, Stöckli and Vidale [10] found a prolonged growing season in Europe over the past two decades. Similar results were also found in North America and China based on the same satellite dataset [11, 12]. Regarding groundbased phenological change, Menzel et al. [14] did a systematic assessment of European phenological responses to climate change and found the spring and summer phenophases such as timing of leaf unfolding and flowering had advanced by a mean trend of 2.5 days/decade from 1971 to 2000 . Such earlier spring phenophases in recent decades were also found in North America [18]. In East Asia, several studies showed clear phenological responses to climate change in Japan and South Korea based on ground observations $[13,19,20]$. In China, although some work has been done to assess phenological changes in several locations [16, 21-24], systematic studies of phenological shifts at a national scale over a long time period are still lacking.

In China, phenological observations have been conducted by the Chinese Phenological Observation Network (CPON) in 1963. Since that time, phenophases of typical 
TABLE 1: Species selected and corresponding observation sites in the study. Site numbers correspond to site numbers shown in Figure 1.

\begin{tabular}{lcc}
\hline Species & Numbers of sites & Distribution sites (site number) \\
\hline Fraxinus chinensis & 3 & $9,15,28$ \\
Ailanthus altissima & 7 & $8,9,12,14,15,17,21$ \\
Melia azedarach & 16 & $14,15,17,18,23,24,24,25,26,29,30,31,33$ \\
Paulownia tomentosa & 15 & $9,10,13,15,18,19,20,21,24,25,26,28,29,30,32$ \\
Ulmus pumila & 18 & $1,2,3,4,5,6,7,8,9,10,11,12,14,15,16,17,18,28$ \\
\hline
\end{tabular}

plant species at each site of the CPON network were monitored by relevant local organizations, such as botanical gardens, weather stations, research institutions, universities, and middle schools. There was no observation, however, carried out in certain periods. Given that discontinuous time series of phenophases affects the assessment of phenological trends, we firstly interpolated the missing phenological data of five widespread woody plants using phenological models. Subsequently, we systematically studied the characteristics of spatiotemporal changes in spring phenology so as to evaluate the specific impacts of climate change on biological systems.

\section{Materials and Methods}

2.1. Phenological and Meteorological Data. Phenological data used in this study were derived from CPON. Spring phenophases of five deciduous woody plants, including Fraxinus chinensis, Ailanthus altissima, Melia azedarach, Paulownia tomentosa, and Ulmus pumila, were investigated. We only used time series with more than 11 years of data from 1963 to 2009. As a result, a total of 33 sites have been included (Figure 1; Table 1). We took first flowering date (FFD) and first leaf date (FLD) as being representative of spring phenophases. According to the uniform observation criteria and guidelines of CPON [25], FFD and FLD are defined as the date when a fixed individual formed its first full flower and first full leaf, respectively. Overall, a total of 118 phenological time series (a phase of a specific species at certain site is considered as one time series) are analyzed (Table 1). As shown in Figure 2, there are a lot of missing data in each year for all phenophases. Especially during the period of 1969-1972, no observation data was made due to the social upheavals of the Cultural Revolution. Similar problems with data collection also existed in the period of 1997-2002 due to funding shortages. The available data (a total of 2316 observations) could only account for $41.8 \%$ of the full dataset (118 time series $\times 47$ years), so these missing data would significantly affect the results of trend estimates. Thus, we interpolated the missing data using phenological models. Although these interpolated phenological data may introduce considerable bias into the results, these uncertainties could be quantified in our analyses (see Section 2.2).

Meteorological data were derived from the Chinese Meteorological Administration (http://cdc.cma.gov.cn/) and included daily mean temperatures from 33 meteorological stations (Figure 1). Most of these meteorological stations are relatively close to the corresponding phenological sites

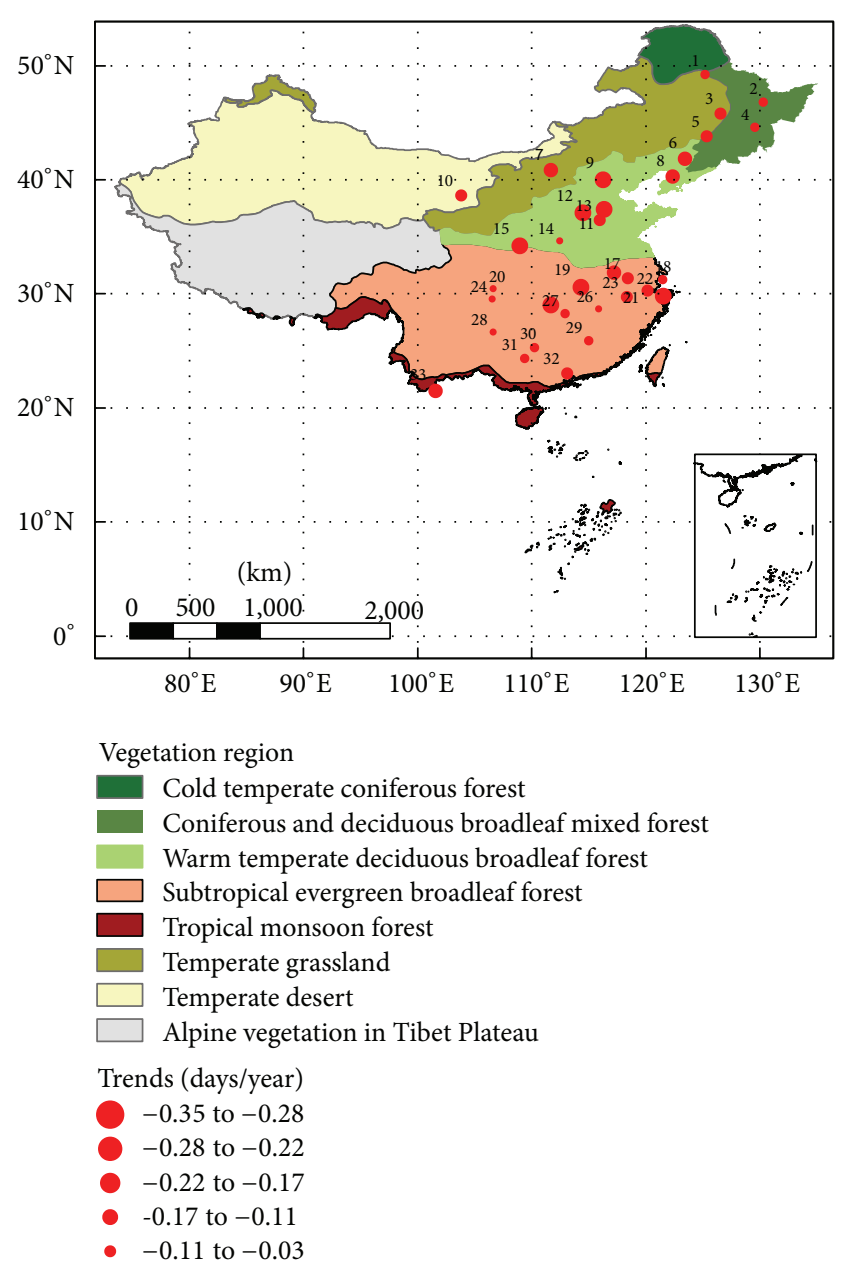

FIGURE 1: Illustration of phenological observation sites and spring phenological trends at each site. Site numbers are shown.

(usually less than $5 \mathrm{~km}$ ), though for site 8 the corresponding phenological site is about $30 \mathrm{~km}$ away.

2.2. Interpolation of Discontinuous Series Using Phenological Models. The spring phenophase of a number of trees has been modeled successfully using accumulated forcing units, which are often calculated by the accumulated degree days above a threshold temperature, regardless of the presence of the additional constraint of a chilling requirement [26]. Since climates over the study area vary in type from site to site, the most applicable models are bound to be different in different places. Thus, we developed two types of models for each 


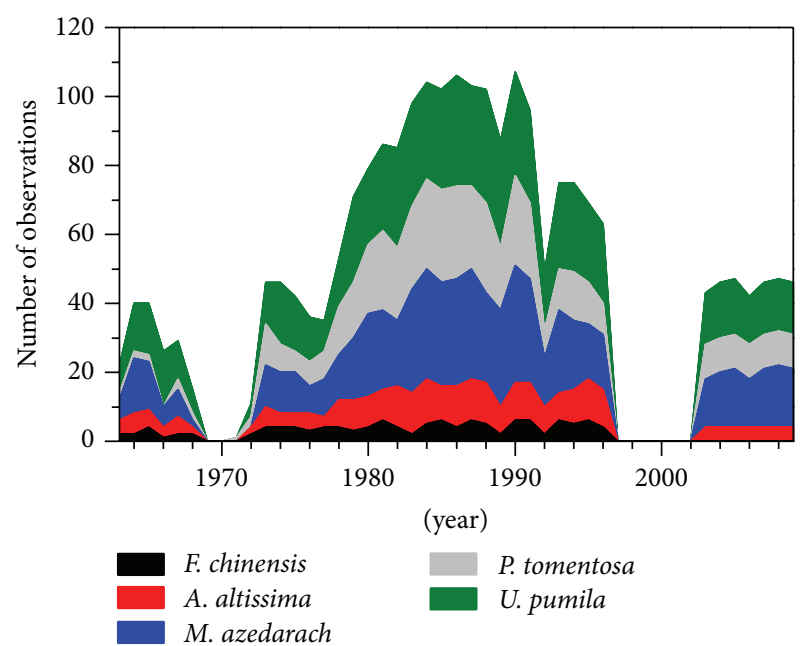

FIGURE 2: Number of phenological observations (including first leaf date and first flowering date) for five plant species from 1963 to 2009.

phenological time series and then chose the most accurate one to interpolate the time series. The first model used is the spring warming (SW) model, which is a model without the constraint of a chilling requirement [27]. Regarding the models with the constraint of a chilling requirement, we chose the UniChill model developed by Chuine [28].

2.2.1. SW Model. In the SW model, plant development occurs in response to aggregated heat sums, or heating degree days (HDD), measured as the sum of $R_{f}\left(x_{t}\right)$ (daily mean temperature $x_{t}$ above a base temperature $T_{b}$ ), starting at a day of year $t_{0}$ (1). The HDD achieve the critical forcing temperature $\left(F^{*}\right)$ at time $t_{y}$, which represent the FFD or FLD that occurred. The equations for SW model are

$$
\begin{gathered}
\mathrm{HDD}=\sum_{t_{0}}^{t_{y}} R_{f}\left(x_{t}\right)=F^{*} \\
R_{f}\left(x_{t}\right)= \begin{cases}0 & \text { if } x_{t} \leq T_{b} \\
x_{t}-T_{b} & \text { if } x_{t}>T_{b} .\end{cases}
\end{gathered}
$$

2.2.2. UniChill Model. The UniChill model divided the process of bud development into two phases: dormancy and quiescence. Dormancy refers to the physiological state during which development and cell growth are prevented by internal factors despite favorable external conditions [29]. Plants enter the phase of quiescence (during which development and cell growth are triggered by warm temperature) when dormancy is broken. The equations are as follows:

$$
\begin{aligned}
& S_{c}=\sum_{t_{0}}^{t_{1}} R_{c}\left(x_{t}\right)=C^{*} \\
& S_{f}=\sum_{t_{1}}^{t_{b}} R_{f}\left(x_{t}\right)=F^{*}
\end{aligned}
$$

$$
\begin{gathered}
R_{c}\left(x_{t}\right)=\frac{1}{1+e^{a\left(x_{t}-c\right)^{2}+b\left(x_{t}-c\right)}} \\
R_{f}\left(x_{t}\right)=\frac{1}{1+e^{d\left(x_{t}-e\right)}},
\end{gathered}
$$

with $t_{0}$ set at September 1 , and seven species-specific parameters $\left(a, b, c, d, e, C^{*}, F^{*}\right)$ fitted to phenological observations. Parameters $a, b$, and $c$ define the response function to temperature $R_{c}\left(x_{t}\right)$, also called "chilling units", which models the effect of "cold" temperatures in breaking dormancy (4). The accumulative sum of chilling units is called the state of chilling $\left(S_{c}\right)$. Parameter $C^{*}$ is the $S_{c}$ threshold at which bud dormancy is broken (2). Parameters $d$ and $e$ define the response function to temperature $\left(R_{f}\left(x_{t}\right)\right.$, also called "forcing units" which conditions the effect of "warm" temperatures during quiescence (5). Forcing units are accumulated as soon as $C^{*}$ is reached at $t_{1}$. The model predicts that phenophase $\left(T_{b}\right)$ occurs when the state of forcing $\left(S_{f}\right)$ reaches a particular critical value $F^{*}(3)$.

The above two models were both fitted for respective species at each site using daily mean temperatures and the FLD or FFD time series through the least square method. The function $f(x)=\sum_{i}\left[r_{i}(P)\right]^{2}$ is minimized in the parameter space $P$, where $r_{i}(P)$ is the residual:

$$
r_{i}(P)=d_{i}(P)-d_{\text {iobs }}
$$

with $d_{i}(P)$ and $d_{\text {iobs }}$ being the simulated date and the observed date in the year $i$, respectively. We only used odd years of each time series to fit the parameters. The internal validity of each series was measured by the percentage variance explained by the model $\left(R^{2}\right)$ and the root mean square error (RMSE) between the observed dates and the simulated dates.

The external validity was also measured by the $R^{2}$ and RMSE between remaining observed dates in even years and corresponding simulated dates. The external validity measures the goodness of simulation for the years not used to fit the parameters, so the uncertainties of models could be represented by the RMSE of external validity. Between two models we chose the optimal one (with fewest uncertainties) to interpolate the missing data. In addition, in order to minimize the errors, only the time series with associated uncertainties less than seven days (RMSE of external validity $<7)$ were retained for further analysis.

2.3. Estimation and Comparison of the Phenological Trends. The temporal trends of time series could be calculated as the slope coefficient of a linear regression model with phenophases as the dependent variable and years as the independent variable. Subsequently, we calculated the mean trend of all the phenological time series for each site and investigated the spatial difference of phenological changes in China. Finally, based on the mean phenological series for all five species across the 33 sites, we applied the MannKendall trend test method for detecting monotonic trends in phenological time series [30]. In addition, we used a movingtrend analysis method to investigate the temporal evolution of phenological trends [31], that is, calculating the regression 
TABLE 2: Internal and external validity of optimal model for 92 time series of spring phenophases. Each column shows the mean \pm standard deviation.

\begin{tabular}{|c|c|c|c|c|c|c|c|}
\hline \multirow{2}{*}{ Species } & \multirow{2}{*}{ Phase } & \multirow{2}{*}{$N$} & \multirow{2}{*}{ DOY } & \multicolumn{2}{|c|}{ Internal validity } & \multicolumn{2}{|c|}{ External validity } \\
\hline & & & & $R^{2}$ & RMSE & $R^{2}$ & RMSE \\
\hline \multirow{2}{*}{ Fraxinus chinensis } & FFD & 2 & $101.9 \pm 12.2$ & $0.41 \pm 0.18$ & $3.3 \pm 0.3$ & $0.31 \pm 0.18$ & $4.6 \pm 1.6$ \\
\hline & FLD & 2 & $100.3 \pm 13.9$ & $0.78 \pm 0.29$ & $2.4 \pm 1.5$ & $0.75 \pm 0.28$ & $3.3 \pm 1.0$ \\
\hline \multirow{2}{*}{ Ailanthus altissima } & FFD & 5 & $140.1 \pm 9.9$ & $0.69 \pm 0.18$ & $2.4 \pm 1.2$ & $0.42 \pm 0.21$ & $3.6 \pm 0.5$ \\
\hline & FLD & 7 & $105.9 \pm 10.0$ & $0.69 \pm 0.15$ & $3.3 \pm 1.0$ & $0.77 \pm 0.12$ & $3.4 \pm 1.5$ \\
\hline \multirow{2}{*}{ Melia azedarach } & FFD & 16 & $111.2 \pm 19.2$ & $0.67 \pm 0.28$ & $3.6 \pm 1.8$ & $0.66 \pm 0.22$ & $4.1 \pm 1.6$ \\
\hline & FLD & 9 & $89.3 \pm 19.7$ & $0.67 \pm 0.28$ & $3.9 \pm 1.4$ & $0.55 \pm 0.28$ & $4.7 \pm 1.4$ \\
\hline \multirow{2}{*}{ Paulownia tomentosa } & FFD & 9 & $89.3 \pm 16.7$ & $0.85 \pm 0.17$ & $2.3 \pm 0.9$ & $0.69 \pm 0.18$ & $3.4 \pm 1.3$ \\
\hline & FLD & 12 & $94.8 \pm 15.2$ & $0.74 \pm 0.17$ & $4.4 \pm 2.3$ & $0.59 \pm 0.21$ & $4.6 \pm 1.1$ \\
\hline \multirow{2}{*}{ Ulmus pumila } & FFD & 13 & $82.0 \pm 23.8$ & $0.63 \pm 0.34$ & $4.2 \pm 2.1$ & $0.60 \pm 0.17$ & $5.2 \pm 1.4$ \\
\hline & FLD & 17 & $103.4 \pm 19.1$ & $0.59 \pm 0.21$ & $4.1 \pm 1.1$ & $0.63 \pm 0.23$ & $4.1 \pm 1.2$ \\
\hline Overall & & 92 & N/A & $0.67 \pm 0.24$ & $3.7 \pm 1.7$ & $0.62 \pm 0.22$ & $4.2 \pm 1.4$ \\
\hline
\end{tabular}

slope for each 31-year period by moving the center year with a step length of one year. For highlighting the decadal variation of spring phenophases, the anomalies (relative to the mean over the 1963-1990 period) of spring phenophases in each decade (1960s, 1970s, 1980s, 1990s, and 2000s) were calculated.

\section{Results}

3.1. Validity of the Models. The SW model performed better (the RMSE of external validity is less) than the UniChill model in 67 time series, while the UniChill model showed better simulation in the other 51 time series. For each time series of spring phenophases, we used the optimal model to interpolate the missing data. In order to minimize the uncertainty of the interpolation as far as possible, we only retained the time series with models uncertainties less than 7 days. As a result, 92 of 118 time series were chosen for further analysis. The results of model validity for these series are shown in Table 2 . The average $R^{2}$ of internal validity for each phenophase ranged from 0.41 to 0.85 with an overall mean of 0.67 , while the overall mean of $R^{2}$ for external validity was 0.62 (0.31-0.77). Accordingly, the overall mean of RMSE for internal validity and external validity was 3.7 days and 4.2 days, respectively. The variances of phenophases (standard deviation) were often more than 3 times stronger than the RMSE (Table 2); therefore, the error introduced by the models was acceptable.

3.2. Spatial Patterns of Spring Phenophases Change. The frequency distribution of the phenological trends is summarized in Figure 3. 88 of 92 spring phenological series showed earlier trends (62 series reached a 0.05 level of significance). Therefore, the earlier trends of spring phenophases from 1963 to 2009 are notable in China. The temporal trends of spring phenophases ranged from -0.35 to -0.03 days/year among different sites (Figure 1). The trends of spring phenophases in the main areas of China are as follows:
(1) The spring phenophases in the Northeast China Plain, represented by sites 1-6 and 8, showed a strongly earlier trend of 0.18 days/year;

(2) the spring phenophases in the North China Plain, represented by sites 9 and 11-13, exhibited a very marked trend of -0.28 days/year, which was the strongest change in China;

(3) the spring phenophases in the Middle-Lower Yangtze Plain, represented by sites 17-19, 21-23, and 26-28, advanced by a mean trend of 0.21 days/year. In the southern part of this area, however, the trends in spring phenophases were relatively weak (e.g., trends at sites 26 and 27 are only -0.07 and -0.14 days/year, resp.);

(4) mean spring phenophases trend in the area of the Yunnan-Guizhou Plateau (represented by site 28) and the Sichuan Basin (represented by sites 20 and 24) was only -0.04 days/year, which was the weakest change in China;

(5) the spring phenophases in the South China area (represented by sites 29-32) advanced by 0.14 days/year.

Furthermore, the spring phenophases at other sites also showed consistent shifts (Figure 1). For example, the spring phenophases at site 7 (Hohhot), the only site located in the temperate grassland region, showed a trend of -0.22 days/year, while the spring phenophases at site 10 (Minqin), located in the temperate desert region, showed an advancing trend of 0.18 days/year. The trend at site 14 (Luoyang), located in the Yi-Luo River Basin, demonstrated a very weak trend ( -0.07 days/year). The mean trend of -0.28 days/year at site 15 (Xi'an), located in the Weihe River Plain, was comparable with the trend in the North China Plain area. Site 33 (Mengla), the only one located in the tropical monsoon forest area, shows an obvious trend of -0.23 days/year towards earlier spring. Overall, the spring phenophases for most areas over China had advanced very significantly, but the strength of the advance varied among different regions. 


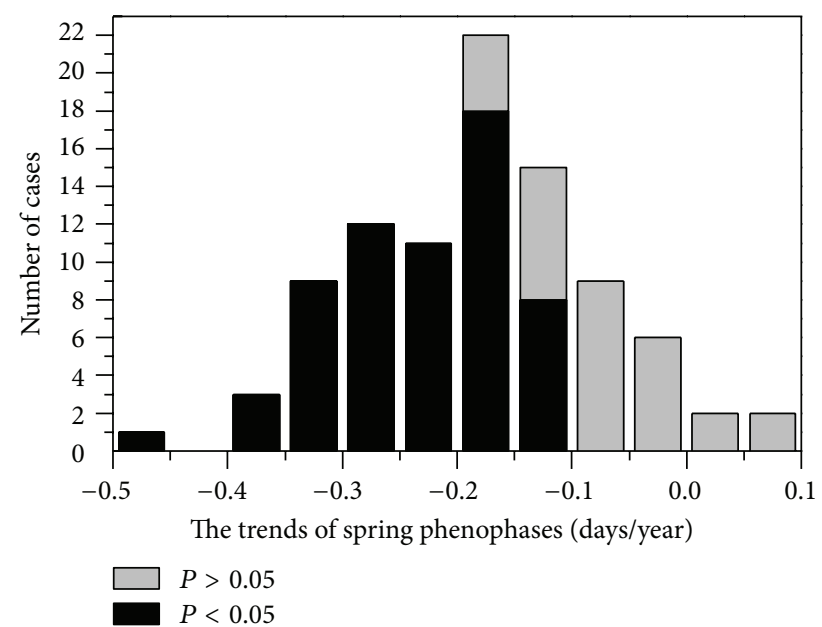

FIGURE 3: Frequency distributions of trends (1963-2009) in spring phenophases. Solid values in columns represent significant trends $(P<0.05)$

3.3. Temporal Evolutions of Spring Phenophases. The annual changes of mean spring phenophases are shown in Figure 4(a). We found that the spring phenophases have large interannual variation with about 18 days' amplitude. In the context of the last 47 years, 1980 marks the latest spring phenophases and 2002 marks the earliest spring phenophases. The spring phenophase in 1980 was 5.0 days later than the 1963-1990 average, while the spring phenophase in 2002 was 13.2 days earlier than the 1963-1990 average. For the overall period of 1963-2009, the linear trend of spring phenophases was -0.18 days/year $(P<0.001)$, suggesting a significant advance of 8.3 days. The Mann-Kendall trend test also indicates a significantly earlier trend in the mean spring phenophases time series $(Z=-3.72 ; P<0.001)$.

The 31-year moving linear analysis of the spring phenological series indicated that the time periods would affect the estimation of phenological trends (Figure 4(b)). The spring phenophases showed a pronounced advancing trend of 0.30 days/year for the period of 1979-2009. The 31-year periods with the center year from 1989 to 1993 also showed significant advancing trends of around 0.23 days/year, though they were less than the trend over the 1979-2009 period (Figure 4(b)). In the 31-year periods with the center year before 1989, the trends of spring phenophases were insignificant. In general, the trends in the recent 31 years showed an unusual advancing trend that surpasses all previously observed trends in the past 31-year periods before 1979.

Furthermore, in terms of the temporal evolution of spring phenophases, a very apparent decadal change was detected (Figure 5). The spring phenophases in the 1990s and 2000s occurred 2.53 and 6.93 days earlier, respectively, than the 1963-1990 average. However, in the first three decades (1960s-1980s) the spring phenophases were close to the 19631990 average. Therefore, the advances in spring phenology can be said to have become evident after the 1980s and then strengthened in the 2000s.

\section{Discussion}

The significant advance in FFD and FLD of the five tree species observed in this study is consistent with spring phenophase changes in other parts of the world (Table 3). In Europe, an enormous systematic phenological network dataset of more than 100000 observational series of 542 plants indicates an advance of 0.25 days/year in spring/summer phase for the period of 1971-2000 [14]. In this study, when restricting the time period to 1971-2000, the spring phenophase trend ( -0.11 days/decade) is shown to be weaker than that observed in Europe (Table 3). Compared with the Northeastern US, however, the observed trend in the flowering time of lilac from 1965 to 2001 is close to our estimates [32]. This evidence indicates that the onset of spring across the Northern Hemisphere has appeared earlier over the past several decades. In the Southern Hemisphere, Australia has also experienced a warming climate in recent decades, leading to earlier wine grape maturity dates with a trend of -0.8 days/year (1985-2009) [33], which is about two times a stronger advance than indicated by spring phenophases in China ( -0.43 days/year).

In addition, another study from China suggested that the spring started 0.41 days earlier per year on average from 1982 to 2006 [34]. The result is stronger than our estimates $(-0.33$ days/year, Table 3 ) over the same period. The possible reason is that both the number of plant species and phenological observation sites involved are different from those relied on in this study. In [34], the authors discussed the FLD of 13 plant species at 20 observation sites, while our study consists of FLD and FBD for five plant species at 33 sites. Therefore, differences in species and phases selection, as well as distribution of phenological observation sites, could affect the results of trend estimates.

The advance of spring phenophases in China has obvious regional differences. In general, the trends in northern China are stronger than those in southern China (Figure 1). As a previous study suggested, the trend of annual temperature increase (1961-2000) was about $0.2-0.3^{\circ} \mathrm{C} /$ decade in northern China and less than $0.1^{\circ} \mathrm{C} /$ decade in southern China [35]. Therefore, in China, the phenological response to climate change matches the observed warming pattern. However, the distribution of phenological observation sites involved in this study is uneven, so these sites have limited spatial representativeness. In future, it will be necessary to enlarge CPON and enlist volunteers to help acquire more phenological data, which could minimize the effect of site distribution in estimating phenological change.

Apart from the temperature in spring and the chilling temperature in winter, the photoperiod and evaporative demand also play an important role in regulating the growth and development of plants in temperate regions $[36,37]$. Decreasing day lengths are reliable cues of the impending end of the growing season and winter onset for many temperate biomes, while increasing day lengths indicate the arrival of spring [37]. Because photosynthesis and growth are likely to be significantly limited if the vapor pressure deficit (VPD) is at a high value [38], the distribution of vegetation with different phenological patterns is very sensitive to seasonal 


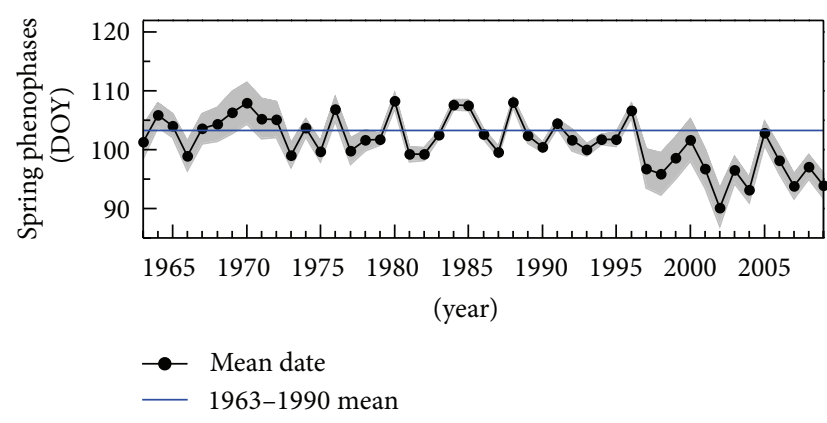

(a)

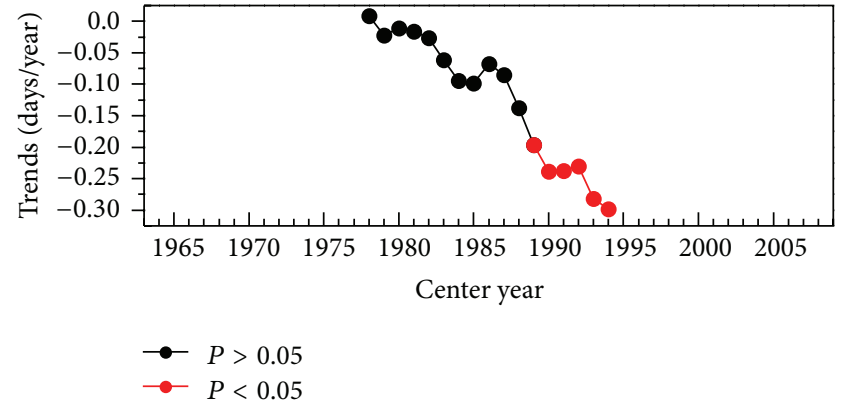

(b)

Figure 4: The change of spring phenophases from 1963 to 2009 (a) and the 31-year moving trends of the spring phenophases (b) in China. The statistically significant trends $(P<0.05)$ are marked with red circles.

TABLE 3: Comparison of trends in spring phenophases between this study and other studies based on ground phenological observations.

\begin{tabular}{|c|c|c|c|c|c|}
\hline Regions & Objects & Periods & Trends (days/year) & Trends in this study & Source \\
\hline Europe & Spring/summer events of 542 plant & $1971-2000$ & -0.25 & -0.11 & {$[14]$} \\
\hline Northeastern USA & The flowering time of lilac & $1965-2001$ & -0.09 & -0.12 & {$[32]$} \\
\hline Australia & Wine grape maturity date & 1985-2009 & -0.80 & -0.43 & {$[33]$} \\
\hline China & The leaf unfolding time of 13 plant species & $1982-2006$ & -0.41 & -0.36 & {$[34]$} \\
\hline
\end{tabular}

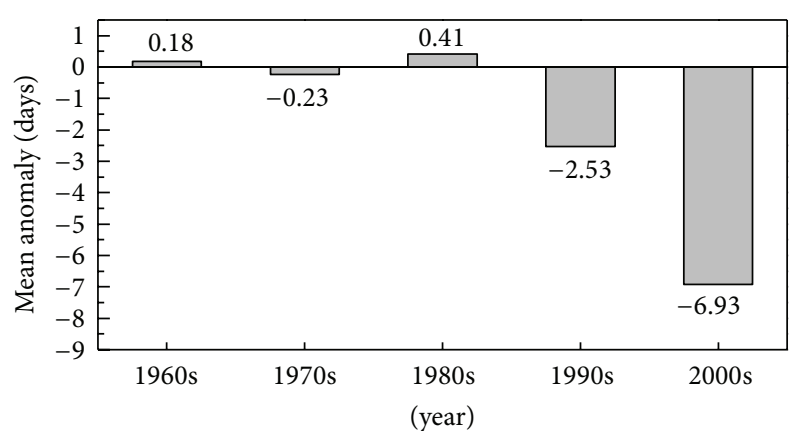

FIGURE 5: The spring phenology anomaly (relative to the 1963-1990 mean) in 1960s (1963-1970), 1970s (1971-1980), 1980s (1981-1990), 1990s (1991-2000), and 2000s (2001-2009).

changes in VPD. Among such influencing factors, the SW model used in this study only considers the effects of spring temperature, but the UniChill model also considers chilling requirements. Thus, the impacts of other potential factors on the model's predictions need to be further studied.

\section{Conclusions}

Based on observational data from CPON, this study investigated the changes in FFD and FLD of five woody plants (including Fraxinus chinensis, Ailanthus altissima, Melia azedarach, Paulownia tomentosa, and Ulmus pumila) in China. The results show that the spring phenophases in China became remarkably earlier at a mean rate of 0.18 days/year over the period from 1963 to 2009. The spring phenophases were stable from the 1960s to the 1980s but advanced by 2.5 days during the 1990s and 6.9 days during the 2000s (compared to the 1963-1990 mean). In addition, the changes of spring phenophases showed noticeable regional difference. The magnitudes of advance in the North China Plain, the Middle-Lower Yangtze Plain, and the Northeast China Plain are the strongest, while the magnitudes of advances in the Yunnan-Guizhou Plateau, the Sichuan Basin, and South China are weaker. In general, the change of spring phenophases in China matches the warming pattern observed over the past 50 years.

\section{Conflict of Interests}

The authors declare that there is no conflict of interests regarding the publication of this paper.

\section{Acknowledgments}

This study is supported by Strategic Leader Project in Science and Technology, Chinese Academy of Sciences (XDA05090301), National Natural Science Foundation of China (41030101 and 41171043), and the National Basic Research Program of China (2012CB955304).

\section{References}

[1] M. D. Schwartz, Phenology: An Integrative Environmental Science, Kluwer Academic Publishers, Dordrecht, The Netherlands, 2003.

[2] C. Parmesan and G. Yohe, "A globally coherent fingerprint of climate change impacts across natural systems," Nature, vol. 421, no. 6918 , pp. 37-42, 2003.

[3] G.-R. Walther, "Plants in a warmer world," Perspectives in Plant Ecology, Evolution and Systematics, vol. 6, no. 3, pp. 169-185, 2004. 
[4] E. E. Cleland, I. Chuine, A. Menzel, H. A. Mooney, and M. D. Schwartz, "Shifting plant phenology in response to global change," Trends in Ecology and Evolution, vol. 22, no. 7, pp. 357365, 2007.

[5] J. Peñuelas, "Phenology feedbacks on climate change," Science, vol. 324, no. 5929, pp. 887-888, 2009.

[6] J. T. Morisette, A. D. Richardson, A. K. Knapp et al., “Tracking the rhythm of the seasons in the face of global change: phenological research in the 21 st century," Frontiers in Ecology and the Environment, vol. 7, no. 5, pp. 253-260, 2009.

[7] S. Piao, P. Friedlingstein, P. Ciais, N. Viovy, and J. Demarty, "Growing season extension and its impact on terrestrial carbon cycle in the Northern Hemisphere over the past 2 decades," Global Biogeochemical Cycles, vol. 21, no. 3, Article ID GB3018, 2007.

[8] A. D. Richardson, T. A. Black, P. Ciais et al., "Influence of spring and autumn phenological transitions on forest ecosystem productivity," Philosophical Transactions of the Royal Society B: Biological Sciences, vol. 365, no. 1555, pp. 3227-3246, 2010.

[9] R. Stöckli, T. Rutishauser, D. Dragoni et al., "Remote sensing data assimilation for a prognostic phenology model," Journal of Geophysical Research G: Biogeosciences, vol. 113, no. 4, Article ID G04021, 2008.

[10] R. Stöckli and P. L. Vidale, "European plant phenology and climate as seen in a 20-year AVHRR land-surface parameter dataset," International Journal of Remote Sensing, vol. 25, no. 17, pp. 3303-3330, 2004.

[11] W. Zhu, H. Tian, X. Xu, Y. Pan, G. Chen, and W. Lin, "Extension of the growing season due to delayed autumn over mid and high latitudes in North America during 1982-2006," Global Ecology and Biogeography, vol. 21, no. 2, pp. 260-271, 2012.

[12] X. Wu and H. Liu, "Consistent shifts in spring vegetation greenup date across temperate biomes in China, 1982-2006," Global Change Biology, vol. 19, no. 3, pp. 870-880, 2013.

[13] C.-H. Ho, E.-J. Lee, I. Lee, and S.-J. Jeong, "Earlier spring in Seoul, Korea," International Journal of Climatology, vol. 26, no. 14, pp. 2117-2127, 2006.

[14] A. Menzel, T. H. Sparks, N. Estrella et al., "European phenological response to climate change matches the warming pattern," Global Change Biology, vol. 12, no. 10, pp. 1969-1976, 2006.

[15] H. Doi and I. Katano, "Phenological timings of leaf budburst with climate change in Japan," Agricultural and Forest Meteorology, vol. 148, no. 3, pp. 512-516, 2008.

[16] J. Dai, H. Wang, and Q. Ge, "Multiple phenological responses to climate change among 42 plant species in Xian, China," International Journal of Biometeorology, vol. 57, no. 5, pp. 749758, 2013.

[17] N. L. Bradley, A. C. Leopold, J. Ross, and W. Huffaker, "Phenological changes reflect climate change in Wisconsin," Proceedings of the National Academy of Sciences of the United States of America, vol. 96, no. 17, pp. 9701-9704, 1999.

[18] M. S. Abu-Asab, P. M. Peterson, S. G. Shetler, and S. S. Orli, "Earlier plant flowering in spring as a response to global warming in the Washington, DC, area," Biodiversity and Conservation, vol. 10, no. 4, pp. 597-612, 2001.

[19] H. Doi and M. Takahashi, "Latitudinal patterns in the phenological responses of leaf colouring and leaf fall to climate change in Japan," Global Ecology and Biogeography, vol. 17, no. 4, pp. 556$561,2008$.
[20] H. Doi, "Response of the Morus bombycis growing season to temperature and its latitudinal pattern in Japan," International Journal of Biometeorology, vol. 56, no. 5, pp. 895-902, 2012.

[21] J. Bai, Q. Ge, and J. Dai, “The response of first flowering dates to abrupt climate change in Beijing," Advances in Atmospheric Sciences, vol. 28, no. 3, pp. 564-572, 2011.

[22] Q. Ge, J. Dai, J. Zheng et al., "Advances in first bloom dates and increased occurrences of yearly second blooms in eastern China since the 1960s: further phenological evidence of climate warming," Ecological Research, vol. 26, no. 4, pp. 713-723, 2011.

[23] J. Zheng, Q. Ge, Z. Hao, and W.-C. Wang, "Spring phenophases in recent decades over eastern china and its possible link to climate changes," Climatic Change, vol. 77, no. 3-4, pp. 449-462, 2006.

[24] X. Chen and L. Xu, "Phenological responses of Ulmus pumila (Siberian Elm) to climate change in the temperate zone of China," International Journal of Biometeorology, vol. 56, no. 4, pp. 695-706, 2012.

[25] M. W. Wan and X. Z. Liu, China's National Phenological Observational Criterion, Science Press, Beijing, China, 1979.

[26] I. Chuine, P. Cour, and D. D. Rousseau, "Selecting models to predict the timing of flowering of temperate trees: implications for tree phenology modelling," Plant, Cell and Environment, vol. 22, no. 1, pp. 1-13, 1999.

[27] A. F. Hunter and M. J. Lechowicz, "Predicting the timing of budburst in temperate trees," Journal of Applied Ecology, vol. 29, no. 3, pp. 597-604, 1992.

[28] I. Chuine, "A unified model for budburst of trees," Journal of Theoretical Biology, vol. 207, no. 3, pp. 337-347, 2000.

[29] E. E. Cleland, I. Chuine, A. Menzel, H. A. Mooney, and M. D. Schwartz, "Shifting plant phenology in response to global change," Trends in Ecology and Evolution, vol. 22, no. 7, pp. 357365, 2007.

[30] S. Yue, P. Pilon, and G. Cavadias, "Power of the Mann-Kendall and Spearman's rho tests for detecting monotonic trends in hydrological series," Journal of Hydrology, vol. 259, no. 1-4, pp. 254-271, 2002.

[31] T. Rutishauser, J. Luterbacher, F. Jeanneret, C. Pfister, and H. Wanner, "A phenology-based reconstruction of interannual changes in past spring seasons," Journal of Geophysical Research G: Biogeosciences, vol. 112, no. 4, Article ID G04016, 2007.

[32] D. W. Wolfe, M. D. Schwartz, A. N. Lakso, Y. Otsuki, R. M. Pool, and N. J. Shaulis, "Climate change and shifts in spring phenology of three horticultural woody perennials in northeastern USA," International Journal of Biometeorology, vol. 49, no. 5, pp. 303-309, 2005.

[33] L. B. Webb, P. H. Whetton, and E. W. R. Barlow, "Observed trends in winegrape maturity in Australia," Global Change Biology, vol. 17, no. 8, pp. 2707-2719, 2011.

[34] T. Ma and C. Zhou, "Climate-associated changes in spring plant phenology in China," International Journal of Biometeorology, vol. 56, no. 2, pp. 269-275, 2012.

[35] W. Qian and A. Qin, "Spatial-temporal characteristics of temperature variation in China," Meteorology and Atmospheric Physics, vol. 93, no. 1-2, pp. 1-16, 2006.

[36] W. M. Jolly, R. Nemani, and S. W. Running, "A generalized, bioclimatic index to predict foliar phenology in response to climate," Global Change Biology, vol. 11, no. 4, pp. 619-632, 2005. 
[37] A. M. Wilczek, L. T. Burghardt, A. R. Cobb, M. D. Cooper, S. M. Welch, and J. Schmitt, "Genetic and physiological bases for phenological responses to current and predicted climates," Philosophical Transactions of the Royal Society B: Biological Sciences, vol. 365, no. 1555, pp. 3129-3147, 2010.

[38] W. M. Jolly, R. Nemani, and S. W. Running, "A generalized, bioclimatic index to predict foliar phenology in response to climate," Global Change Biology, vol. 11, no. 4, pp. 619-632, 2005. 

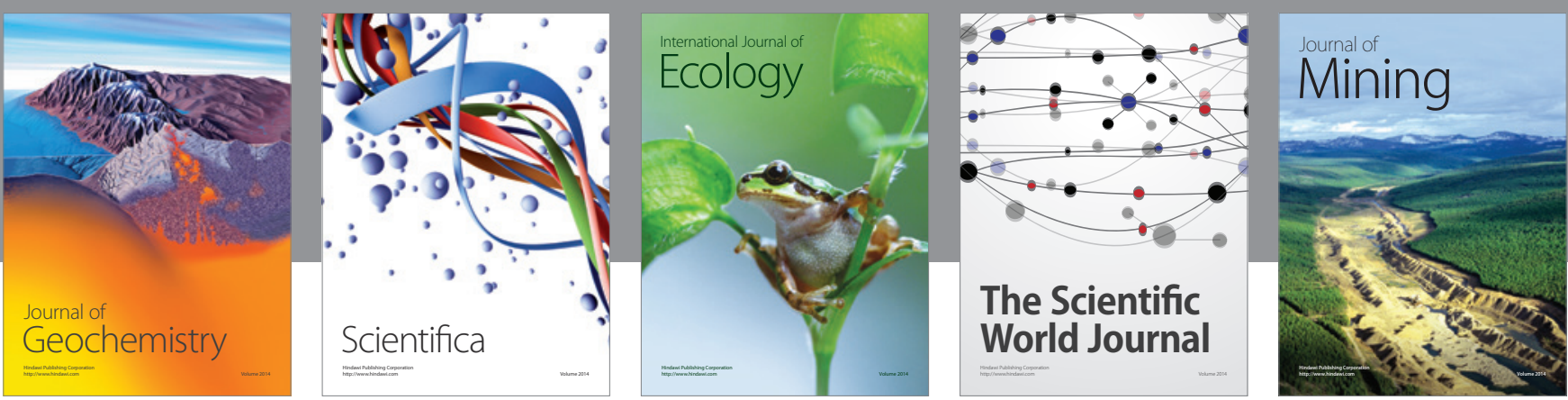

The Scientific World Journal
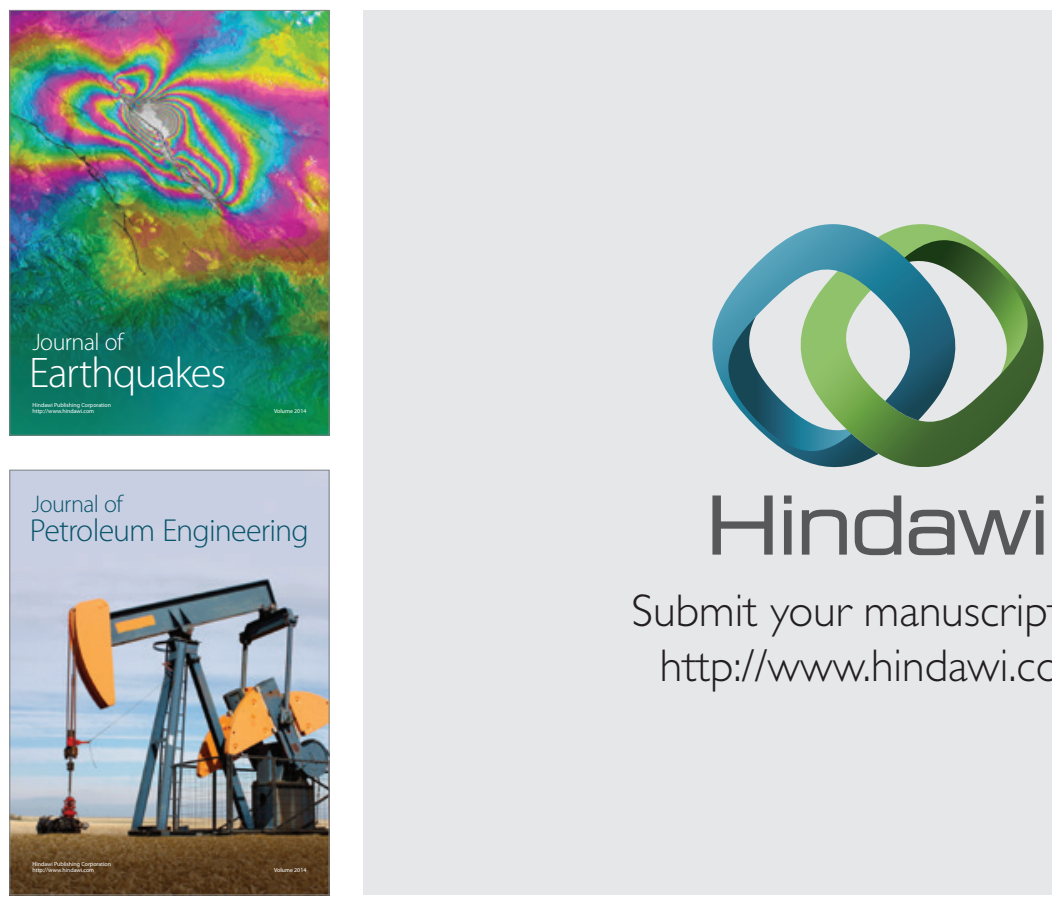

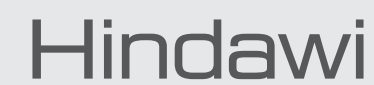

Submit your manuscripts at

http://www.hindawi.com
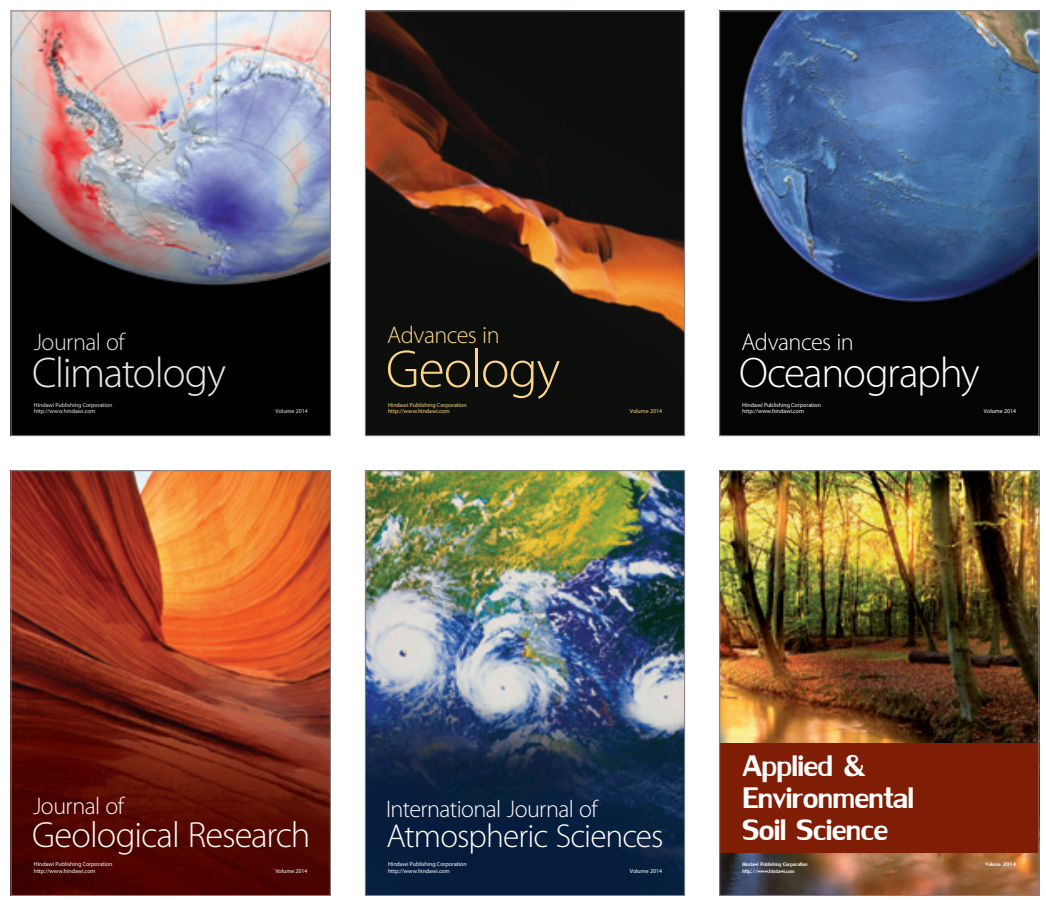
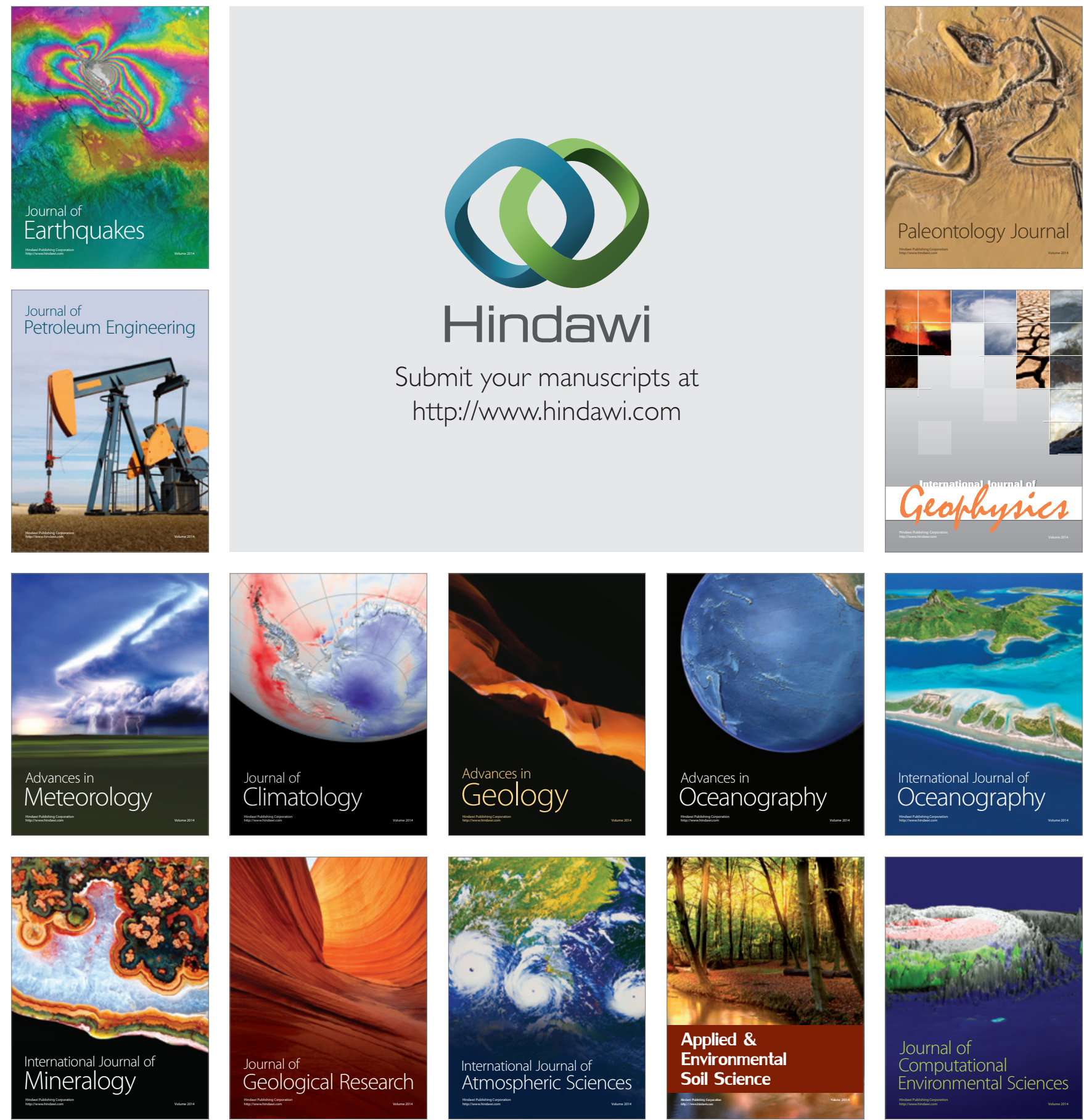